\title{
Caracterização e avaliação preliminar da ecotoxicidade de resíduo de indústrias de papelão
}

\author{
Preliminary characterization and ecotoxicity assessment of paperboard industry waste
}

\author{
Nádia da Silva*, Júlia Carina Niemeyer, Joni Stolberg \\ Universidade Federal de Santa Catarina, Curitibanos, SC, Brasil. *Autor para correspondência: nadia.silva1103@gmail.com.
}

Submissão: 20/09/2018 / Aceite: 10/12/2019

\begin{abstract}
RESUMO
A indústria de papel e papelão é geradora de resíduos sólidos que demandam correto tratamento e disposição. $O$ trabalho teve por objetivo caracterizar a composição de resíduos de duas empresas de papelão de Santa Catarina e avaliar sua ecotoxicidade. A caracterização foi feita com a determinação da umidade, cinzas e celulose. A ecotoxicidade foi avaliada com ensaios de fuga com minhocas (Eisenia andrel), ensaios de reprodução com colêmbolos (Folsomia candida) e com um teste de germinação e crescimento de raízes de alface (Lactuca sativa). Para as avaliações dos ensaios de toxicidade utilizou-se a ANOVA seguida dos testes de Tukey e/ou Dunnet e o teste exato de Fisher todos à $p<0,05$. Os Resíduos 1 e 2 apresentaram umidade de 87,23 e $60,80 \%$, cinzas 11,18 e $55,12 \%$ e celulose 59,34 e $66,78 \%$, respectivamente. Os ensaios de fuga e de reprodução não indicaram ecotoxicidade dos resíduos estudados para minhocas e colêmbolos quando comparados ao solo de plantio de pinus. Em relação ao crescimento de raízes, o Resíduo 1 apresentou toxicidade para as concentrações de 100, 75 e 50\% do seu elutriato. Os resultados indicaram que os resíduos possuem características químicas, físicas e ecotoxicológicas que podem ser restritivas quanto a sua aplicação em solos agrícolas.
\end{abstract}

PALAVRAS-CHAVE: ensaios de ecotoxicidade, indústria de papelão, lodo de ETE.

\begin{abstract}
Paper and paperboard industry generate solid waste that demands correct treatment or disposal. The objective of this work was to characterize the solid waste of two paperboard industries located in Santa Catarina and to assess its ecotoxicity. The characterization involved the determination of moisture, ashes, and cellulose content. Ecotoxicity tests included avoidance behavior tests with earthworms (Eisenia andrel), reproduction tests with collembolans (Folsomia candida), and a test of germination and growth of roots of lettuce (Lactuca sativa). Results of the ecotoxicity tests were assessed using ANOVA followed by tests of Tukey and Dunnett and Fisher exact test $(p<0.05)$. Wastes 1 and 2 presented moisture of 87.23 and $60.80 \%$, ashes 11.18 and $55.12 \%$, and cellulose 59.34 and $66.78 \%$, respectively. Avoidance and reproduction tests did not indicate ecotoxicity for earthworms and collembolans when compared to the soil from pinus plantation. Concerning lettuce root growth, Waste 1 showed toxicity for the concentrations of 100,75 , and $50 \%$ of its elutriate. The results indicated that the wastes have chemical, physical, and ecotoxicological characteristics that may be restrictive for their application on agricultural soils.
\end{abstract}

KEYWORDS: ecotoxicological testes, cardboard industry, ETE sludge.

Associado ao crescimento da produção industrial, ocorre o aumento da quantidade de resíduos gerados e aumenta-se também a necessidade de viabilizar uma solução para o tratamento e utilização desses resíduos (STIJEPOVIC \& LINKE 2011). Um dos grandes desafios das indústrias é a disposição final dos seus resíduos, os quais geralmente são destinados a aterros e lixões (ALVES et al. 2012). Para as indústrias do setor florestal, o destino mais econômico e ecologicamente correto poderia ser a reutilização no ciclo de produção. Porém, essa alternativa muitas vezes não é possível, obrigando as indústrias a buscarem outras formas de descarte (SANTOS et al. 2013, TOLEDO et al. 2015). Outra prática bastante comum é o descarte de resíduos em solos agrícolas, pois é uma alternativa economicamente viável e, sendo bem conduzida, é considerada ambientalmente correta (SMITH 2009).

A indústria de papel e celulose se destaca como um dos tipos de indústrias que mais causam impactos ao ambiente, todavia representa um dos mais expressivos setores industriais do mundo. Em Rev. Ciênc. Agrovet., Lages, SC, Brasil (ISSN 2238-1171) 
relação à reutilização de papel, o Brasil está entre os principais recicladores do mundo (ALVES et al. 2012). No ano de 2016, estima-se que 4,8 milhões de toneladas de papel retornaram ao processo produtivo, esse reaproveitamento leva à economia de insumos, em especial da água utilizada nos processos de produção a partir da celulose (BRACELPA 2011, IBÁ 2017). No processo de reciclagem, as principais matérias primas são aparas e o principal resíduo gerado é o lodo proveniente das Estações de Tratamento de Efluentes ETE's (ALVES et al. 2012).

Na produção de papel a partir da reciclagem são utilizadas diferentes classificações de aparas, que na sua composição apresentam cargas e aditivos, tais como cola, caulim, sulfato de alumínio, amido e anilinas, adesivos e látex. Também é comum a presença de pigmentos, que interferem na alvura do papel e de muitas fibras de papel rejeitadas no processo de produção. Estas cargas e aditivos, que são removidos ao longo do processo, são encaminhados à ETE, gerando posteriormente os resíduos sólidos da ETE (SCHNEIDER \& MÜHLEN 2011), que são geralmente classificados como Classe II (ABNT 2004a). Como o volume dos resíduos vem crescendo constantemente nas fábricas, elas estão buscando alternativas para utilização do lodo, como por exemplo, servir como fonte de adubação ou corretivo de acidez em áreas agrícolas e florestais (PINHEIRO 2008). Entretanto, na mesma proporção com que são enfatizadas as vantagens agrícolas, existe a possível presença de elementos e substâncias potencialmente tóxicas, orgânicas ou inorgânicas, nesses resíduos (PIRES \& MATTIAZZO 2008).

Os ensaios ecotoxicológicos são importantes ferramentas para avaliar o grau de toxicidade que um resíduo pode apresentar para os organismos e ecossistemas aquáticos e terrestres (CARDOSO \& ALVES 2012). Enquanto as análises químicas confirmam a presença dos contaminantes, os ensaios ecotoxicológicos quantificam e qualificam os efeitos para os organismos, auxiliando na determinação de concentrações que não causem risco para o ecossistema. Em sua maioria, os ensaios feitos com organismos da fauna do solo são baseados em respostas de letalidade, reprodução, crescimento e comportamento, após o contato com solos contaminados (CESAR et al. 2013, SEGAT 2015).

A atividade dos organismos edáficos está envolvida em uma gama de processos ecossistêmicos que contribuem direta e indiretamente para diversos serviços ambientais, tais como, estrutura do solo, crescimento das plantas, ciclagem de nutrientes e decomposição da matéria orgânica (BROWN et al. 2015). Algumas substâncias químicas alteram o comportamento dos organismos, seja por efeitos na sobrevivência e reprodução, ou mesmo causando fuga, o que pode ser avaliado em ensaios laboratoriais (CANDELLO 2014). Muitos vegetais também são utilizados para avaliação de impactos ambientais devido às suas características nutritivas e fisiológicas, também pelo fato de que as raízes das plantas absorvem sais minerais, água e podem acabar absorvendo alguma substância tóxica presente no ambiente, o que pode levar a diminuição das chances de sobrevivência e desenvolvimento das mesmas. A alface (Lactuca sativa Linnaeus 1753) é um exemplo desses organismos-teste, amplamente utilizada nos estudos de ecotoxicidade devido à sua sensibilidade a agentes químicos, rápida germinação e crescimento linear em ampla faixa de variação de $\mathrm{pH}$. Os ensaios com alface permitem que os efeitos fitotóxicos possam ser analisados através de diferentes variáveis como, por exemplo, germinação, alongamento de raiz e biomassa vegetal (GOMES et al. 2012, BAGLIANO 2012).

A partir disso, considera-se importante avaliar a toxicidade do resíduo das empresas de papelão para conhecer o risco que oferecem ao ambiente e para orientar sua destinação correta. O presente trabalho teve por objetivo realizar uma caracterização preliminar de resíduos de indústrias de papelão, através da determinação da umidade, cinzas e celulose neles presentes, e realizar também uma avaliação preliminar de ecotoxicidade em laboratório através de ensaios ecotoxicológicos normatizados.

Foram selecionados resíduos de ETE de duas empresas produtoras de papelão localizadas no Estado de Santa Catarina. A Empresa 1 situada no município de Curitibanos, utiliza como matéria prima aparas de papel, mas também refile de papel ondulado, celulose branqueada e refile de pinus e araucária. A Empresa 2, que se encontra localizada no município de Guatambu, utiliza apenas aparas de papel na produção. Os resíduos foram coletados com o auxílio de uma pá em vários pontos do monte ou local onde os mesmos se encontravam (ABNT 2004b). Para o presente trabalho o resíduo nomeado como Resíduo 1 (R1) é proveniente da Empresa 1 e o Resíduo 2 (R2) da Empresa 2.

\section{Caracterização dos resíduos}

Para a determinação da umidade dos resíduos, foram pesadas $2 \mathrm{~g}$ de cada amostra diretamente nas cápsulas, previamente taradas, as quais foram secas em estufa a $105 \pm 3^{\circ} \mathrm{C}$ durante 48 horas. $\mathrm{O}$ teor de umidade foi calculado a partir da Equação 1, onde $U$ representa a umidade que é expressa em porcentagem do peso inicial da amostra, Pu representa o peso úmido da amostra e Ps o peso seco da amostra (ABNT 2003). 


$$
U=\left(\frac{P u-P S}{P u}\right) \times 100 \quad \text { Equação } 1
$$

O teor de cinzas foi determinado com $2 \mathrm{~g}$ do resíduo úmido para cada amostra; os cadinhos com as amostras foram colocados na mufla a $525{ }^{\circ} \mathrm{C} \pm 25{ }^{\circ} \mathrm{C}$ por três horas. Dessa massa foi retirada a umidade calculada anteriormente obtendo-se assim, o Peso da Amostra Seca (Pas). Após a combustão, aguardou-se por três horas para que o material orgânico das amostras fosse totalmente incinerado. $O$ cálculo para determinação do teor de cinzas presente nos resíduos foi determinado pela Equação 2, onde Tc é o teor percentual de cinzas da amostra, Pac o peso das amostras após a combustão, Pc representa o peso do cadinho e Pas o peso da amostra seca (ABNT 2003).

$$
T c=\left(\frac{P a c-P c}{P a s}\right) \times 100 \quad \text { Equação } 2
$$

O conteúdo de celulose também foi determinado para a caracterização dos resíduos. Para isso realizou-se o refluxo de $5 \mathrm{~g}$ do resíduo seco em estufa a $110^{\circ} \mathrm{C}$ por 24 horas, durante uma hora em uma solução de ácido nítrico. Posteriormente a esse período de refluxo, o material foi filtrado e aquecido em água destilada, e extraído com uma solução aquosa de $\mathrm{NaOH}$. Após a extração o mesmo foi lavado com água destilada, depois com ácido acético e novamente com água. Posteriormente à lavagem, o resíduo foi levado à estufa para secagem e pesado em balança analítica. Para o cálculo do teor de celulose utilizou-se a Equação 3, onde TCe representa o teor de celulose presente no resíduo, Ps é o peso da amostra inicial seca e Pae é o peso da amostra após a extração (ABREU et al. 2006). As determinações de umidade, cinzas e celulose foram feitas em triplicata.

$$
T C e=\frac{P a e}{P_{S}} \times 100
$$

Equação 3

\section{Avaliações ecotoxicológicas dos resíduos}

A avaliação ecotoxicológica foi realizada com o ensaio de fuga utilizando minhocas da espécie Eisenia andrei Bouché, 1972, para este ensaio utilizou-se caixas plásticas, divididas em duas seções de mesma área com o auxílio de um divisor plástico. Cada seção recebeu $250 \mathrm{~g}$ de solo. Uma seção foi preenchida com o solo-teste (solo com resíduo) e a outra com solo não contaminado (solo coletado em área de plantio de Pinus taeda, localizada próximo ao Campus da UFSC Curitibanos). O solo de pinus foi usado como controle e também nas diluições buscando-se maior relevância ecológica na avaliação, uma vez que as empresas do ramo, incluindo uma das que teve o resíduo estudado no presente trabalho, tem feito uso do resíduo para adubação dos plantios de pinus. Após a remoção deste divisor, 10 organismos adultos de peso visualmente semelhante e clitelo bem desenvolvido foram introduzidos na interface entre os solos.

$O$ teste de fuga foi executado em três tratamentos para cada um dos resíduos analisados, sendo um deles com os resíduos brutos versus o solo de pinus ( $\mathrm{R} 1$ e $\mathrm{R} 2 \times \mathrm{Co}$ ), o outro correspondia à mistura de 80 t/ha do resíduo misturado ao solo de pinus versus o solo de pinus (80 t/ha R1 e R2 x Co). Essa concentração de 80 t/ha foi escolhida considerando uma alta dose aplicada a campo, trabalhando com o pior cenário possível de aplicação, para verificar se provocaria algum efeito sobre os organismos da fauna do solo. Também foi usado um controle que recebeu solo de pinus dos dois lados da caixa (Co $x$ Co), para verificar a distribuição aleatória das minhocas na caixa-teste. Cada tratamento contou com cinco réplicas. $O$ teste foi mantido sob temperatura controlada $\left(20 \pm 1^{\circ} \stackrel{\circ}{\circ}\right)$ e fotoperíodo de luz: escuridão $(16: 8 \mathrm{~h})$. Após 48 horas de exposição, foi verificado o número de animais no solo-controle e no solo-teste. Se mais de $80 \%$ dos organismos evitaram o solo-teste, considerou-se que o solo possui "função de habitat limitada" (ABNT 2011a).

Realizou-se também o ensaio de reprodução com colêmbolos (Folsomia candida Willem, 1902) (ABNT 2011b). Os resíduos foram testados na sua forma bruta, em uma mistura de 80 t/ha dos resíduos em solo de pinus, solo de pinus e o solo artificial tropical (SAT), solo normatizado, utilizado em ensaios de ecotoxicidade para validação dos ensaios. Cada replicata foi composta de um recipiente plástico e uma tampa, e cada uma recebeu $30 \mathrm{~g}$ de solo dos respectivos tratamentos e 10 colêmbolos com idade entre $10 \mathrm{e}$ 12 dias. $\mathrm{O}$ ensaio permaneceu incubado à temperatura de $20 \pm 1{ }^{\circ} \mathrm{C}$ durante 28 dias. Os colêmbolos foram alimentados no $1^{\circ}$ e no $14^{\circ}$ dia com fermento biológico (Saccharomyces cerevisiae Hansen 1883) e realizou-se também a manutenção da umidade de cada uma das réplicas. Ao final deste período, foram adicionadas água e tinta de caneta (deixa o meio mais escuro e facilita a visualização dos colêmbolos, que são brancos) a cada uma das réplicas, possibilitando o registro fotográfico dos juvenis e, posteriormente, fez-se a contagem dos organismos utilizando o programa Image $J^{\circledR}$ descrito por RASBAND (1997). 
Ainda para a avaliação ecotoxicológica dos resíduos realizou-se o ensaio de germinação e crescimento de raízes de sementes de alface (Lactuca sativa). O mesmo foi realizado com o elutriato dos resíduos (ABNT 2004c). O teste de germinação com sementes de $L$. sativa foi realizado em cinco tratamentos para cada um dos resíduos, nos quais um era o controle e os outros quatro as diluições do elutriato nas proporções de 25, 50, 75 e 100\%. Para cada tratamento realizou-se três repetições. Em placas de Petri, forradas com papel de filtro, foram adicionados $2 \mathrm{~mL}$ do elutriato e distribuídas 10 sementes de alface. As placas fechadas foram mantidas a uma temperatura de $20 \pm 2 \stackrel{\circ}{\circ}$ e ao abrigo da luz por um período de 72 horas. Ao final deste período foi realizada a contagem da quantidade de sementes germinadas em cada placa. Fez-se ainda a medição do comprimento de raiz emitido por cada uma das sementes de cada um dos tratamentos testados. As medições foram realizadas com o auxílio de régua graduada, para uma posterior análise estatística dos dados (ANDRADE et al. 2010).

Para avaliar a germinação e comprimento de raízes das sementes de alface utilizou-se a Análise de Variância (ANOVA) e teste de Tukey $(p<0,05)$. Para a reprodução utilizou-se a ANOVA em seguida teste de Dunnet $(p<0,05)$. Para ambos conjuntos de dados foram cumpridos os pressupostos da ANOVA, não se verificou nenhum outlier entres os valores e tanto dos dados de comprimento de raízes quanto os de reprodução de colêmbolos apresentaram distribuição normal segundo o teste de Shapiro-Wilk $(p<0,05)$. Para a avaliação do ensaio de fuga utilizou-se o teste exato de Fisher $(p<0,05)$. As análises estatísticas foram realizadas a partir de linguagem de programação $R$ ( $R$ DEVELOPMENT CORE TEAM 2013).

\section{Caracterização dos resíduos}

Os Resíduos 1 e 2 apresentaram, respectivamente, umidade de 87,23 e 60,80\%, esses valores podem ser observados na Tabela 1 , juntamente com os teores de cinzas e celulose para ambos os resíduos. Essa diferença de umidade observada entre os resíduos, está relacionada ao fato de que a Empresa 1 realiza apenas o adensamento do lodo após sua coagulação. Já a Empresa 2, além do adensamento realiza também o desaguamento do lodo para aumentar o teor de sólidos, o qual é realizado utilizando a técnica do filtro prensa.

Tabela 1. Teores de umidade, cinzas e celulose presentes nos Resíduos 1 e 2. Table 1. Moisture, ash and cellulose contents present in Waste 1 and 2.

\begin{tabular}{crrrrrr}
\hline & \multicolumn{2}{c}{ Umidade (\%) } & \multicolumn{2}{c}{ Cinzas (\%) } & \multicolumn{2}{c}{ Celulose (\%) } \\
& $\mathrm{R} 1$ & $\mathrm{R} 2$ & $\mathrm{R} 1$ & $\mathrm{R} 2$ & $\mathrm{R} 1$ & $\mathrm{R} 2$ \\
\hline Média & 87,28 & 60,80 & 11,18 & 55,12 & 59,34 & 66,78 \\
Desvio Padrão & 0,43 & 0,75 & 1,23 & 0,47 & 1,80 & 0,80 \\
\hline
\end{tabular}

KAWATOKO \& RIZK (2010) ao estudarem um lodo de ETE de uma indústria de reciclagem de papel para tratamento por compostagem obtiveram um teor de umidade para o resíduo de $93,82 \%$, valor esse superior ao que se encontrou para o Resíduo 1 (87,23\%). Segundo os autores, os altos teores de umidade presentes nesses tipos de resíduos impossibilitam a utilização do mesmo para compostagem, pois acabam provocando uma alta produção de chorume, além de dificultarem a aeração do sistema o que pode levar a anaerobiose do mesmo. FARIA et al. (2015) estudaram a disponibilidade de macronutrientes em Eucalyptus saligna Smith cultivados com lodo de papel reciclado, no qual o teor de umidade determinado pelo método gravimétrico foi de $60,7 \pm 3,7 \%$ valor próximo ao que se encontrou pelo mesmo método para o Resíduo 2 $(60,80 \%)$.

Para a viabilidade econômica e ambiental da disposição de lodo em aterros industriais recomenda-se uma concentração de sólidos superior a 25\% (DI BERNARDO \& DANTAS 2005), condição esta não atingida pelo Resíduo 1, pois o mesmo apresentou em sua composição $87,27 \%$ de umidade, ou seja, apenas $12,72 \%$ de sólidos.

Em relação aos valores de cinzas, os mesmos são bastante distintos entre os resíduos, pois para o Resíduo 1 o valor médio de cinzas foi de $11,18 \%$, enquanto para Resíduo 2 o valor médio foi de $55,12 \%$ (Tabela 1).

FERREIRA (2012) ao analisar o lodo da ETE de uma empresa que produz papel Tissue (papéis de baixa gramatura) encontrou uma quantidade de $55,54 \%$ de cinzas, resultado esse muito superior ao encontrado para o Resíduo 1, porém bastante próximo ao valor encontrado para o Resíduo 2. A empresa estudada por FERREIRA (2012) tem como matéria prima papel reciclado, assim como a Empresa 2. Já a Empresa 1 além de papel reciclado utiliza também celulose branqueada e refile de pinus e araucária no seu processo, o que pode ser uma explicação para as diferenças encontradas. GUAITOLINI (2014) estudando a queima do lodo secundário da indústria de celulose em caldeira de leito fluidizado, encontrou um percentual 
de cinzas de $8,4 \%$. O autor coloca que, para a queima, a mistura deve ser a mais uniforme possível em suas características fundamentais, como teores de umidade e cinzas, já que a queima de lodos muito ricos em cinzas gera baixa energia térmica e problemas de incrustações nas caldeiras.

Dos resíduos avaliados neste trabalho, caso fossem utilizados para queima em caldeiras, o Resíduo 1 apresentaria menos problemas de incrustação e geraria mais energia térmica que o Resíduo 2 que apresentou um alto teor de cinzas (Tabela 1). ODA (2017) trabalhando com produção, caracterização e aplicação de carvão ativado a partir de lodo biológico de indústrias têxtil e de papel, encontrou um teor de $40,56 \%$ de cinzas para o lodo de papel, o que ele atribuiu ao fato da empresa receber vários tipos de papéis que são entregues, muitas vezes, misturados à areias e solos, o que contribuiria para o alto teor de cinzas. Esse fato poderia explicar o alto teor de cinzas (55,12\%) encontrado para o Resíduo 2 nesta pesquisa. Em relação aos valores de celulose (Tabela 1), os resíduos de ambas as empresas apresentaram mais de 50\% de celulose na sua composição, sendo em média 59,34\% no Resíduo 1 e 66,78\% no Resíduo 2.

KAWATOKO \& RIZK (2011), estudaram o tratamento do lodo gerado na empresa de reciclagem de papel por compostagem. Os autores observaram que o resíduo proveniente da empresa de reciclagem de papel acabou desacelerando o processo de compostagem. Eles assumem que uma das causas dessa redução estaria relacionada ao fato de o lodo apresentar alto teor de celulose.

Os resíduos orgânicos brutos com altos valores de $\mathrm{C} / \mathrm{N}$ quando são aplicados aos solos podem fazer com que os vegetais ali presentes fiquem carentes de nitrogênio. Isso ocorre até que esses materiais sejam completamente decompostos e que a população microbiana presente nesses solos e decompositora desses materiais diminua e a partir da decomposição dos organismos ocorra finalmente a liberação de nitrogênio para as plantas (LEPSCH 2011). Devido ao alto teor de matéria orgânica presente nos resíduos deste estudo, a aplicação dos mesmos no solo pode causar a imobilização de nitrogênio e prejudicar o desenvolvimento das plantas.

\section{Avaliações ecotoxicológicas dos resíduos}

$\mathrm{Na}$ avaliação da ecotoxicidade dos resíduos o ensaio de fuga utilizando a espécie $E$. andrei foi analisado a partir do teste exato de Fisher $(p<0,05)$, segundo o qual, percebeu-se que não houve fuga dos organismos em nenhum dos tratamentos testados (Figura 1). A partir disso, pode-se concluir que os resíduos testados não causaram repulsa das minhocas, quando comparados com o solo do plantio de pinus sem a adição de resíduo.

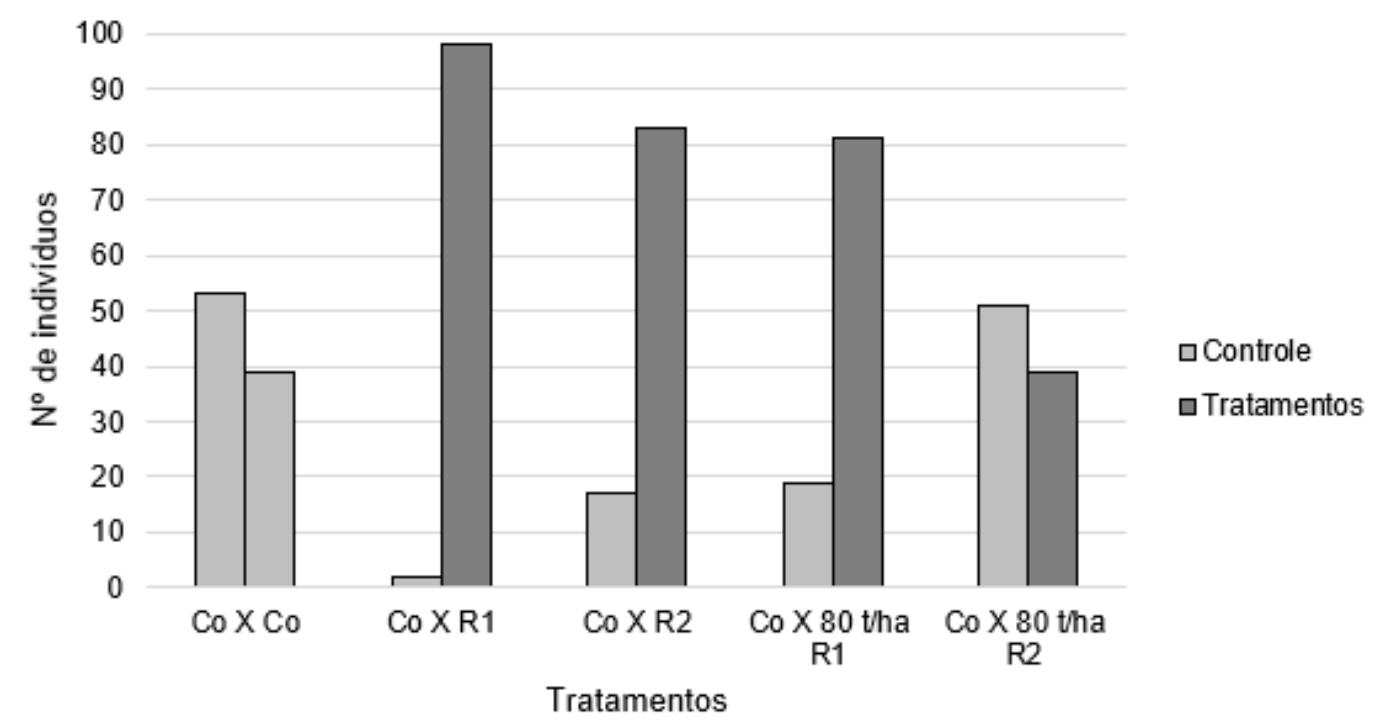

Figura 1. Porcentagem média ( \pm desvio padrão) de indivíduos ( $E$. andrel) encontrados em cada um dos tratamentos comparados com o controle (solo de pinus). $\mathrm{R} 1=$ resíduo $1 . \mathrm{R} 2=$ resíduo 2.

Figure 1. Average percentage ( \pm standard deviation) of individuals ( $E$. andrei) found in each of the treatments compared to the control (pinus soil). $R 1=$ waste $1 . R 2=$ waste 2.

No entanto, segundo DE SILVA \& GESTEL (2009) as minhocas (E. andreı) podem não ser boas indicadoras de toxicidade em solos-testes com altos teores de matéria orgânica, pois são de natureza epigéica e possuem preferência por esses tipos de solos. Uma vez que os resíduos possuem muita matéria orgânica em sua composição, isso significa que no ambiente elas se alimentarão deste material, não havendo repulsa. 
Além disso, o fato de comparar os resíduos e concentrações com solo proveniente de plantios de pinus (controle) pode ter influenciado a preferência dos organismos, pois esses solos apresentam acidez elevada, enquanto os resíduos e suas misturas apresentam valores de $\mathrm{pH}$ mais neutros (resíduos puros) ou menos ácidos (misturas) do que o solo controle, estando mais próximos do $\mathrm{pH}$ ótimo para as minhocas $(5,5-6,5)$. O pH do solo de pinus foi 4,24; do Resíduo 1 bruto foi 7,29 e 80 ton/ha foi 4,68; do Resíduo 2 bruto foi 7,18 e 80 ton/ha foi 4,47 .

FRANCO et al. (2016) realizaram ensaios ecotoxicológicos de fuga com Eisenia fetida Savigny 1826, com lixiviado de aterro sanitário. $O$ teste de fuga foi realizado tomando-se concentrações decrescentes na razão de 50\%, que tiveram como partida a dosagem de $100 \%$ do lixiviado, para a obtenção das concentrações desejadas os lixiviados foram diluídos em água deionizada. Para o substrato comercial, foi identificado que as concentrações até $25 \%$ não causaram fuga dos organismos-teste. Entretanto, observouse que existiu um comportamento de fuga, não tóxico $(<60 \%)$, a partir da concentração $50 \%$ e que a toxicidade (fuga $>60 \%$ ) ocorreu somente com a concentração de $100 \%$. Ao contrário do que se observa para os Resíduos 1 e 2, onde não se observou fuga para nenhum dos resíduos em nenhuma das concentrações testadas (Figura 1).

O ensaio de reprodução de colêmbolos cumpriu os critérios de validação, apresentando um coeficiente de variação $<30 \%$. Os resultados mostraram que para o Resíduo 1 a reprodução foi superior no tratamento de 80 t/ha em relação ao controle, e para o Resíduo 2 a reprodução foi superior no resíduo bruto, ambos em relação ao solo controle. Assim, pode-se afirmar que nenhum dos resíduos apresentou toxidade no ensaio de reprodução de F. candida (Figura 2). CROUAU et al. (2002) alertaram para a dificuldade da avaliação de compostos orgânicos, pois os testes com colêmbolos podem ter diferentes respostas devido a variações ocorridas no $\mathrm{pH}$, teor de umidade e presença de grande quantidade de matéria orgânica nos solos-testes utilizados. O material orgânico pode atuar simultaneamente como recurso nutricional, mas também como uma fonte de toxicidade para esses organismos. Por isso a importância de se realizar ensaios com mais de uma espécie e diferentes endpoints (alvos fisiológicos) para avaliar a toxicidade de um resíduo.

ESPERANÇA (2013) em sua tese avaliou os efeitos da aplicação de fertilizantes orgânicos no crescimento de trigo (Triticum aestivum L.) e nabo (Brassica rapa L.), na atividade biológica do solo e na reprodução de $F$. candida. Os fertilizantes orgânicos testados foram vários, entre eles estrume de vaca, galinha, estrume de frango misturado com substrato de cogumelos frescos e outros. $O$ ensaio foi avaliado por meio da análise de variância (ANOVA) que mostrou diferenças significativas no número de juvenis e no número de adultos entre os diferentes tratamentos testados. O solo com estrume de frango misturado com substrato de cogumelos frescos que apresentava um teor médio-alto de matéria orgânica, apresentou uma maior abundância de juvenis em relação aos outros tratamentos. Já o solo com substrato de cogumelos maturados foi o que apresentou uma taxa de sobrevivência de adultos significativamente inferior e um menor número de juvenis em relação aos outros tratamentos o que comprova que a constituição do solo pode comprometer a reprodução e/ou desenvolvimento da espécie de colêmbolo ( $F$. candida).

Da mesma forma que ESPERANÇA (2013), no ensaio de reprodução de colêmbolos com os Resíduos 1 e 2 também se observa uma reprodução maior dos organismos nos solos de resíduo bruto e no tratamento de $80 \mathrm{t} / \mathrm{ha}$, ou seja, naqueles com maior teor de matéria orgânica (Figura 2). $\mathrm{O} \mathrm{pH}$ também pode ter influenciado na reprodução de colêmbolos, pois os resíduos e concentrações apresentaram maior reprodução em relação ao controle com solo de pinus. Isso pode ter ocorrido, devido ao fato que solos de $\mathrm{pH}$ ácidos (solo de pinus) acabam ocasionando uma menor reprodução desses organismos quando comparados com solos mais básicos, caso dos resíduos.

Para os ensaios de germinação o número de sementes de $L$. sativa germinadas foi de $100 \%$, não havendo diferença estatística significativa em nenhum dos tratamentos dos elutriatos dos Resíduos. Para o endpoint tamanho de raiz, todas as réplicas apresentaram coeficiente de variação $<30 \%$, com exceção das concentrações de R1 de 25 e $75 \%$ e R2 de 25 e $75 \%$ que apresentaram um coeficiente de variação de 33,$74 ; 38,82 \%$ e 47,$79 ; 35,84 \%$, respectivamente. No entanto, em relação ao crescimento de raízes, o elutriato do Resíduo 1 apresentou toxicidade diretamente relacionada a sua concentração. As médias dos tamanhos de raízes são estatisticamente menores que o controle nas concentrações de 50, 75 e 100\% do elutriato do Resíduo 1.

RODRIGUES-CORRÊA et al. (2017) observaram que extratos elaborados a partir de acículas de pinus aplicados em ensaio de germinação de sementes de alface ( $L$. sativa) provocaram inibição da sua germinação, do comprimento de radículas emitidos e dos tamanhos de hipocótilos. Isso ocorreu principalmente quando os extratos foram aplicados nas concentrações mais altas e quando as acículas 
utilizadas eram mais frescas, comprovando que as acículas de pinus apresentaram efeitos fitotóxicos sob as sementes de alface. O Resíduo 1 é originado em uma empresa de papelão que utiliza no processo de produção refiles de pinus, o que poderia estar relacionado a fitoxicidade observada no ensaio de crescimento das raízes para este resíduo (Figura 3).
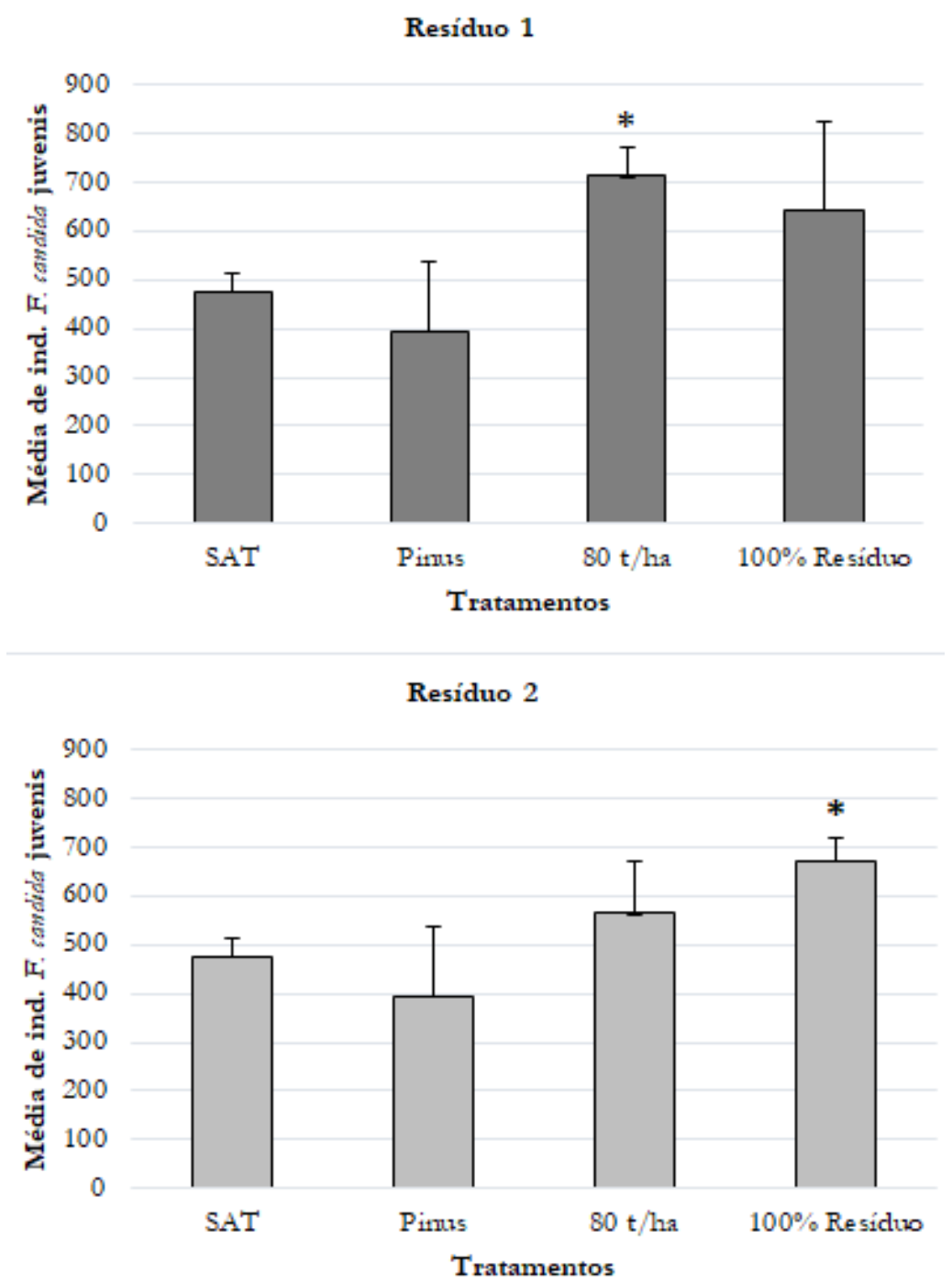

Figura 2. Média ( \pm desvio padrão) de indivíduos juvenis $F$. candida, de cada tratamento testado para os Resíduos 1 e 2. Asterisco indica diferença estatisticamente significativa em relação ao solo de pinus (teste de Dunnet, $p<0,05$ ).

Figure 2. Mean ( \pm standard deviation) ( \pm standard deviation) of juvenile of $F$. candida, from each treatment of Waste 1 and 2. Asterisk indicates a statistically significant difference in relation to pinus soil (Dunnet test, $p<0.05$ ).

A empresa da qual o Resíduo 1 é proveniente, além de trabalhar com aparas de papel, e refiles de pinus como já citado, utiliza também na sua produção refile de araucária e de papel ondulado, além de celulose branqueada. Sabe-se que a produção de celulose branqueada é a principal fonte de toxicidade total das indústrias de papel e celulose. Tendo em vista, que no processo de produção do qual resulta o Resíduo 1 utiliza-se celulose branqueada, então essa diminuição do tamanho de raízes conforme aumentou-se as concentrações de elutriato do resíduo pode estar relacionada a utilização dessa matéria prima que pode dar uma característica fitotóxica ao Resíduo 1.

Em relação ao Resíduo 2, os valores médios para o tamanho de raízes nas concentrações de 75 e $25 \%$ apresentaram-se estatisticamente diferentes do controle. A fitotoxidade observada para este resíduo não foi relacionada à concentração, pois os experimentos com maiores concentrações não apresentaram toxicidade (Figura 3). Diferentemente do Resíduo 1, o Resíduo 2 é proveniente de um processo de produção que faz a utilização apenas de aparas de papel, por esse motivo os resultados para esse ensaio 
podem ter apresentado respostas tão diferentes quando comparados os dois resíduos nas mesmas concentrações.
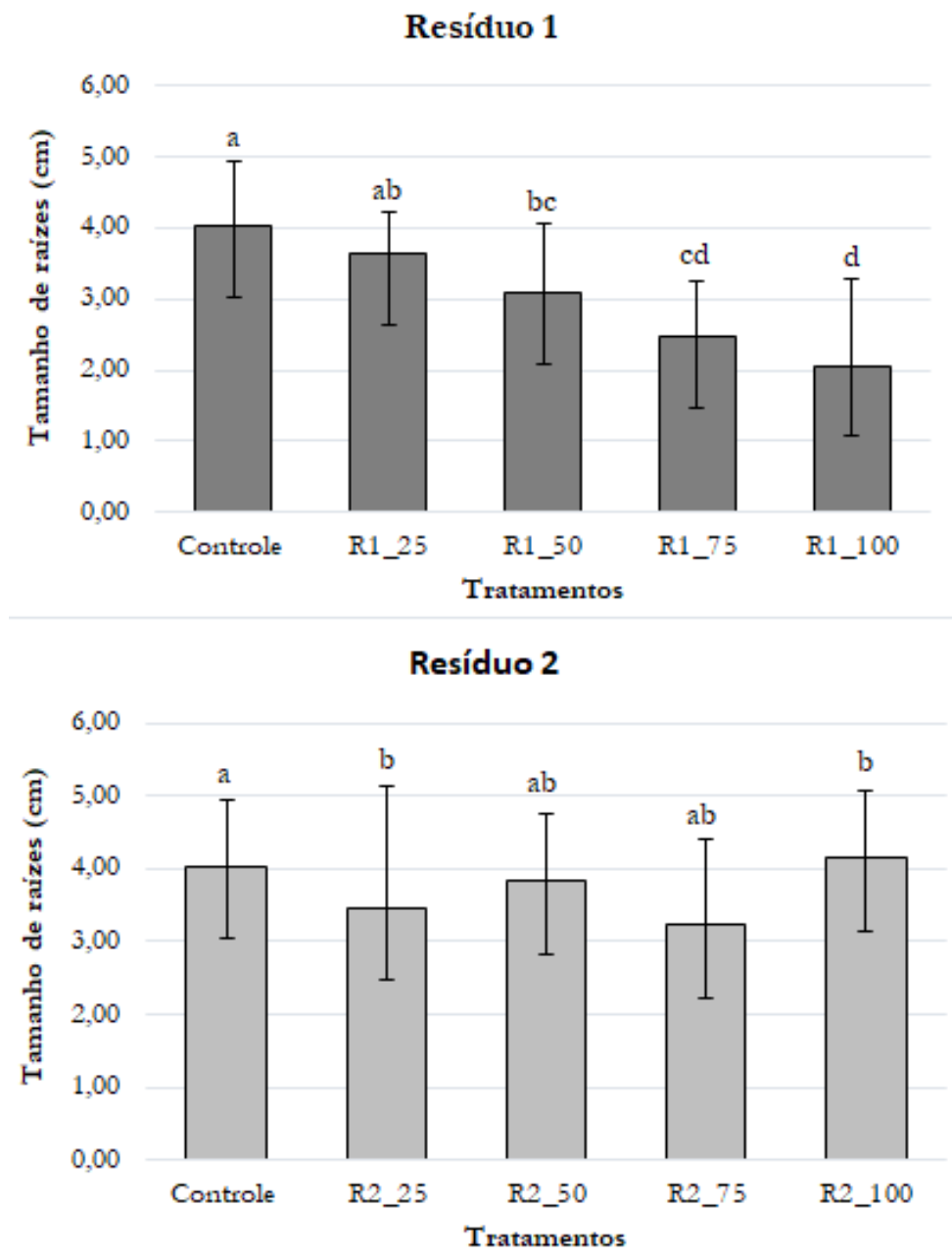

Figura 3. Tamanho de raízes (média \pm desvio padrão) para os tratamentos com os Resíduos 1 e 2 nas concentrações de 25, 50, 75 e 100\%. Letras diferentes indicam diferenças estatisticamente significativas entre os tratamentos (teste de Tukey, $\mathrm{p}<0,05$ ).

Figure 3. Root size (mean \pm standard deviation) for treatments with residues 1 and 2 at concentrations of 25, 50, 75, and 100\%. Different letters indicate statistically significant differences among treatments (Tukey test, $p<0.05$ ).

Nota-se que mesmo trabalhando com resíduos provenientes de empresas do mesmo ramo industrial há diferenças entre eles, pois as matérias primas utilizadas pelas empresas não são exatamente as mesmas, embora ambas trabalhem com aparas de papel. O fato de uma delas utilizar outros tipos de matéria prima pode ter ocasionado as diferenças observadas tanto na caracterização do resíduo como também nos ensaios ecotoxicológicos. Enquanto uma não apresentou toxidade em nenhum dos ensaios realizados, a outra apresentou um indício de toxidade no ensaio com plantas. Essas diferenças podem levar a decisões distintas quanto ao descarte e à possível utilização desses resíduos.

O Resíduo 1, por conta do seu alto teor de umidade, tem restrições quanto à disposição em aterro industrial. Em relação à alta quantidade de celulose encontrada nos resíduos estudados, a aplicação nos solos para fins agrícolas pode causar a imobilização de nitrogênio e prejudicar o desenvolvimento das plantas. Os resultados da avaliação ecotoxicológica indicaram que os resíduos de ambas as empresas não apresentaram toxicidade no ensaio de fuga com minhocas, ensaio de reprodução de colêmbolos ou mesmo para germinação das sementes de alface. No entanto, observou-se um efeito tóxico para o ensaio de comprimentos de raízes das sementes de alface para o Resíduo 1. A inibição de crescimento de raízes para L. sativa observado para o elutriato do Resíduo 1 indicam que estudos adicionais precisam ser realizados para conhecer os efeitos da aplicação dos resíduos em solos agrícolas. Quanto ao Resíduo 2, este estudo preliminar indica potencial uso futuro, e para tanto recomenda-se uma etapa posterior de experimentos em campo, juntamente com análises complementares, para verificar sua eficiência e garantir a proteção do meio ambiente. 


\section{REFERÊNCIAS}

ABNT. 2003. Associação Brasileira de Normas Técnicas. NBR 13999. Papel, cartão, pastas celulósicas e madeira: determinação do resíduo (cinza) após a incineração a $525^{\circ} \mathrm{C} .4 \mathrm{p}$.

ABNT. 2004a. Associação Brasileira de Normas Técnicas. NBR 10004. Resíduos sólidos - Classificação. 71p.

ABNT. 2004b. Associação Brasileira de Normas Técnicas. NBR 10007. Amostragem de resíduos sólidos. 21p.

ABNT. 2004c. Associação Brasileira de Normas Técnicas. NBR 15469. Ecotoxicologia - Coleta, preservação e preparo de amostras. 16p.

ABNT. 2011a. Associação Brasileira de Normas Técnicas. NBR ISO 17512-1. Qualidade do solo - Ensaio de fuga para avaliar a qualidade de solos e efeitos de substâncias químicas no comportamento. Parte 1: Ensaio com minhocas (Eisenia fetida e Eisenia andrei). 26p.

ABNT. 2011b. Associação Brasileira de Normas Técnicas. NBR ISO 11267. Qualidade do solo - Inibição da reprodução de Collembola (Folsomia candida) por poluentes do solo. 18p.

ABREU HS et al. 2006. Métodos de análise em química da madeira. Floresta e Ambiente 5: 1-20.

ALVES I et al. 2012. Gerenciamento dos resíduos sólidos: estudo de caso de uma indústria de papel tissue em Campina Grande - PB. Engenharia Ambiental 9: 51-61.

ANDRADE LF et al. 2010. The effect of cyanide compounds, fluorides aluminum, and inorganic oxides present in spent pot liner on germination and root tip cells of Lactuca sativa. Ecotoxicology and Environmental Safety 73: 626-631.

BAGLIANO RV. 2012. Principais organismos utilizados como bioindicadores relatados com uso de avaliadores de danos ambientais. Revista Meio Ambiente e Sustentabilidade 2: 24-40.

BRACELPA. 2011. Associação Brasileira de Celulose e Papel. Dados do setor. Brasília: BRACELPA. 60p.

BROWN GG et al. 2015. Biodiversidade da fauna do solo e sua contribuição para os serviços ambientais. In: PARRON ML et al. (Ed.). Serviços ambientais em sistemas agrícolas e florestais do Bioma Mata Atlântica. Brasília: Embrapa. p.122-154.

CANDELLO FP. 2014. Comportamento de fuga de minhocas na presença do antimicrobiano sulfadiazina em solo. Dissertação (Mestrado em Engenharia Civil). Campinas: Unicamp. 96p.

CARDOSO EJBN \& ALVES PRL. 2012. Soil Ecotoxicology. Ecotoxicology 33: 27-50.

CESAR RG et al. 2013. Disposição continental de resíduos de mineração de carvão: drenagem ácida, ecotoxicidade aguda e biodisponibilidade de metais. Ecotoxicology Environmental. Contamination 8: 51-61

CROUAU $Y$ et al. 2002. The use of Folsomia candida (Collembola, Isotomidae) in bioassays of waste. Applied Soil Ecology 19: 65-70.

DE SILVA PMCS \& GESTEL CAM. 2009. Comparative sensitivity of Eisenia andrei and Perionyx excavatus in earthworm avoidance tests using two soil types in the tropics. Chemosphere 77: 1609-1613.

DI BERNARDO L \& DANTAS Â.DB. 2005. Métodos e técnicas de tratamento de água. 2.ed. São Carolos: Rima. 788p.

ESPERANÇA ESM. 2013. Serviços ecossistêmicos de um campo agrícola: efeitos da fertilização. Dissertação (Mestrado em Toxicologia e Ecotoxicologia). Portugal: Universidade de Aveiro. 92p.

FARIA ÁBC et al. 2015. Disponibilidade de macronutrientes em Eucalyptus saligna cultivados com lodo de papel reciclado. Floresta 45: 261-272.

FERREIRA AMC. 2012. Aplicação de resíduos de lodo de papel na preparação de compósitos com cinza de madeira e cal residual: caracterização e ensaios normatizados. Tese (Doutorado em Engenharia Mecânica). Curitiba: UFPR. 77p.

FRANCO HA et al. 2016. Aplicação de lixiviado de aterro sanitário em substrato para produção de mudas florestais: uma abordagem ecotoxicológica. In: IV CBRA. Congresso Brasileiro de Reflorestamento Ambiental. Anais... Rio de Janeiro: Reflorestamento Ambiental. p.113-117.

GOMES LS et al. 2012. Ecotoxicity of Sludges Generated by Textile Industries: A Review. Journal of the Brazilian Society of Ecotoxicology 7: 89-96.

GUAITOLINI M. 2014. Estudo da queima do lodo secundário da indústria de celulose em caldeira de leito fluidizado. Dissertação (Mestrado em Tecnologia de Celulose e Papel). Viçosa: UFV. 52p.

IBÁ. 2017. Indústria Brasileira de Árvores. Relatório 2017. São Paulo: IBÁ. 80p.

KAWATOKO IES \& RIZK MC. 2010. Tratamento do lodo gerado na indústria de reciclagem de papel por compostagem. Estudos Tecnológicos 6: 68-81.

KAWATOKO IES \& RIZK MC. 2011. Propostas de tratamento para o lodo de reciclagem de papel em uma indústria de pequeno porte. Engenharia Ambiental 8: 52-68.

LEPSCH IF. 2011. 19 lições de pedologia. 1.ed. São Paulo: Oficina de Textos. 456p.

ODA TYR. 2017. Produção, caracterização e aplicação de carvão ativado a partir de lodo biológico de indústrias têxtil e de papel. Dissertação (Mestrado em Engenharia Civil). Viçosa: UFV. 104p.

PINHEIRO RM. 2008. Reciclagem de resíduo proveniente da produção de papel em cerâmica vermelha. Revista Matéria 13: 220-227.

PIRES AMM \& MATTIAZZO ME. 2008. Avaliação da Viabilidade do Uso de Resíduos na Agricultura. Jaguariúna: Embrapa. 9p.

R DEVELOPMENT CORE TEAM. 2013. R: A Language and Environment for Statistical Computing. Vienna: R Foundation for Statistical Computing.

RASBAND WS. 1997. ImageJ. Maryland: National Institutes of Health.

RODRIGUES-CORREAA KCS et al. 2017. Dual allelopathic effects of subtropical slash pine (Pinus elliottii Engelm.) 
needles: Leads for using a large biomass reservoir. Elsevier 108: 113-120.

SANTOS FEV et al. 2013. Formação de mudas de Eucalyptus urophylla S.T. Blake com utilização de resíduo sólido orgânico urbano. Enciclopédia Biosfera 9: 1203-1214.

SCHNEIDER A \& MÜHLEN CV. 2011. Caracterização cromatográfica de compostos orgânicos presentes nos resíduos provenientes de indústrias de reciclagem de papel e sua aplicação na produção de briquetes e carvão vegetal. Química Nova 34: 1556-1561.

SEGAT JC et al. 2015. Ecotoxicological evaluation of swine manure disposal on tropical soils in Brazil. Ecotoxicology and Environmental Safety 122: 91-97.

SMITH SR. 2009. A critical review of the bioavailability and impacts of heavy metals in municipal solid waste composts compared to sewage sludge. Environment International 35: 142-156.

STIJEPOVIC MZ \& LINKE P. 2011. Optimal waste heat recovery and reuse in industrial zones. Energy 36: 4019-4031.

TOLEDO FHSF et al. 2015. Composto de resíduos da fabricação de papel e celulose na produção de mudas de eucalipto. Revista Brasileira de Engenharia Agrícola e Ambiental 19: 711-716. 